\title{
Letter to the Editor: Diagnostic Value of Virtual Bronchoscopic Navigation in the Bronchial Tuberculosis-Induced Central Airway Stenosis
}

Siamak Sabour

Received: March 18, 2020 / Published online: April 16, 2020

(C) The Author(s) 2020

Keywords: Benign central airway stenosis; Diagnostic value; Electronic bronchoscopy; Tracheobronchial tuberculosis; Virtual bronchoscopic navigation

\section{Key Summary Points}

Without assessing reproducibility (reliability), we cannot talk about diagnostic value of virtual bronchoscopic navigation (VBN).

Sensitivity and specificity can be acceptable; however, considering the rest of validity estimates, our final decision can easily be changed.

Reporting diagnostic added value of VBN by applying receiver operative characteristic curve is crucially important.

Digital Features To view digital features for this article go to https://doi.org/10.6084/m9.figshare. 12098241.

S. Sabour $(\square)$

Department of Clinical Epidemiology, School of Health and Safety, Shahid Beheshti University of Medical Sciences, Tehran, Islamic Republic of Iran e-mail:s.sabour@sbmu.ac.ir

S. Sabour

Safety Promotions and Injury Prevention Research Centre, Shahid Beheshti University of Medical

Sciences, Tehran, Islamic Republic of Iran
To assess diagnostic value of VBN in the diagnosis of benign central airway stenosis (CAS) secondary to tracheobronchial tuberculosis (TBT), methodological and statistical issues should be carefully taken into account; otherwise, misinterpretation of the results may occur.

I was interested to read the paper by Cheng and colleagues that was published in the March 2020 edition of Infectious Diseases and Therapy [1]. Electronic bronchoscopy is invasive and may cause pain. The purpose of the authors was to explore the clinical value of virtual bronchoscopic navigation (VBN) in the diagnosis of benign central airway stenosis (CAS) secondary to tracheobronchial tuberculosis (TBT). The location, length and diameter of stenosis of 68 patients with benign CAS caused by TBT were independently determined by VBN and electronic bronchoscopy (EOB). The sensitivity and specificity of VBN in identifying stenosis were assessed by EOB as the gold standard. The stenosis was graded into $0 \%, \leq 25 \%, 26-50 \%, 51-75 \%, \quad 76-90 \%$ and $>$ $90 \%$. They reported that the sensitivity of VBN in determining the degree of stenosis was $98.4 \%$, $100.0 \%, 100 \%, 100 \%, 84.6 \%$ and $100 \%$, respectively; the specificity was $91.5 \%, 96.1 \%, 97.1 \%$, $97.1 \%, 97.1 \%$ and $97.3 \%$, respectively. They 
concluded that VBN is helpful for the diagnosis of TBT-induced CBS and may provide important information on the location, length, diameter and cross-sectional area of stenosis for further EOB examination and interventional therapy.

First, it is crucial to know that, without assessing reproducibility (reliability, precision, repeatability), we cannot talk about diagnostic value. Reproducibility and validity (accuracy) are two completely different methodological issues of diagnostic value [2]. Second, sensitivity and specificity are among the estimates to assess validity (accuracy) of a diagnostic test, and have nothing to do with reproducibility [2-7]. It should be noted that, due to the limitation of reported values for accuracy (e.g. sensitivity and specificity are generally used for public health purposes and limited in clinical practice), other validity estimates, such as positive predictive value, negative predictive value, and likelihood ratios, should also be taken into account. These estimates are more appropriate for advice about the accuracy of a diagnostic test for clinical purposes. The point is that reported estimates, as in this study, can be acceptable; however, considering the rest of the validity estimates, our final decision can easily be changed. Moreover, none of the above-mentioned estimates can assess reproducibility [2-7]. Third, the receiver operative characteristic curve is usually used to assess diagnostic accuracy (discrimination) of a diagnostic model. However, for clinical purposes, in order to compare two diagnostic tests, reporting diagnostic added value is crucially important. The reason is that all validity estimates can be acceptable, but diagnostic added value may be negligible [2-7]. To sum up, the main clinical points of my letter, in order to assess the diagnostic value of a test, the methodological and statistical issues should carefully be taken into account; otherwise, misinterpretation of the results may occur.

\section{ACKNOWLEDGEMENTS}

Funding. No funding or sponsorship was received for this study or publication of this article.
Authorship. All named authors meet the International Committee of Medical Journal Editors (ICMJE) criteria for authorship for this article, take responsibility for the integrity of the work as a whole, and have given their approval for this version to be published.

Disclosures. Siamak Sabour has nothing to declare.

Compliance with Ethics Guidelines. This article does not contain any studies with human participants or animals performed by any of the authors.

Data Availability. Data sharing is not applicable to this article as no datasets were generated or analyzed during the current study.

Open Access. This article is licensed under a Creative Commons Attribution-NonCommercial 4.0 International License, which permits any non-commercial use, sharing, adaptation, distribution and reproduction in any medium or format, as long as you give appropriate credit to the original author(s) and the source, provide a link to the Creative Commons licence, and indicate if changes were made. The images or other third party material in this article are included in the article's Creative Commons licence, unless indicated otherwise in a credit line to the material. If material is not included in the article's Creative Commons licence and your intended use is not permitted by statutory regulation or exceeds the permitted use, you will need to obtain permission directly from the copyright holder. To view a copy of this licence, visit http:// creativecommons.org/licenses/by-nc/4.0/.

\section{REFERENCES}

1. Cheng LP, Gu Y, Gui XW, Fang Y, Wang H, Sha W. Diagnostic value of virtual bronchoscopic navigation in the bronchial tuberculosis induced central airway stenosis. Infect Dis Ther. 2020;9(1):165-74.

2. Grobbee DE, Hoes AW. Clinical epidemiology: principles, methods, and applications for clinical 
research. 2nd ed. Burlington: Jones and Bartlett; 2015.

3. Szklo M, Nieto FJ. Epidemiology beyond the basics. 3rd ed. Manhattan: Jones and Bartlett; 2014.

4. Sabour S. Reliability of the ASA physical status scale in clinical practice: Methodological issues. Br J Anaesth. 2015;114:162-3.

5. Baharvand M, Manifar S, Akkafan R, et al. Serum levels of ferritin, copper, and zinc in patients with oral cancer. Biomed J. 2014;37(5):331-6.
6. Pirouzpanah S, Taleban FA, Mehdipour P, et al. The biomarker-based validity of a food frequency questionnaire to assess the intake status of folate, pyridoxine and cobalamin among Iranian primary breast cancer patients. Eur J Clin Nutr. 2014;68(3):316-23.

7. Sabour S, Farzaneh F, Peymani P. Evaluation of the sensitivity and reliability of primary rainbow trout hepatocyte vitellogenin expression as a screening assay for estrogen mimics:Methodological issues. Aquat Toxicol. 2015;164:175-6. 